\title{
The Exponential Growth of Social Inequality in Brazil among the SARS-Covid Pandemic19
}

\section{Matos JR* and Morbini FK}

Master in Fundamental Rights and Democracy, Autonomous University Center of Brazil, Brazil

*Corresponding author: Francieli Korquievicz Morbini, Master in Fundamental Rights and Democracy Autonomous University Center of Brazil, University Professor and Lawyer, Brazil, Email: francieli_advocacia@hotmail.com

\section{Opinion \\ Volume 4 Issue 1}

Received Date: February 05, 2021

Published Date: February 22, 2021

DOI: $10.23880 / a b c a-16000162$

\section{Opinion}

The present study analyzes issues inherent to the growth of levels of social inequality in Brazil after the arrival of the Sars-CoV-2 pandemic. Brazil has always been the scene of great social inequalities, especially due to the difficulty of the masses' rise, the precariousness of the teaching conditions and the lack of public policies aimed at reducing it. However, a pandemic revealed an even more perverse and inhumane scenario in Brazilian lands. Vulnerable groups remain in subhuman conditions of survival, left to their own devices amid high probabilities of contamination with the virus. Homeless, poor, miserable, indigenous, quilombolas, riverside, gypsies, refugees, slum dwellers and peripheries, are people who survive as they can in the midst of a pandemic. At the moment, we are facing the epicenter of the pandemic in the world. We experienced in addition to the increase in the number of deaths, the return of information, the consubstantial increase in the price of food, especially food in the basic basket, a real collapse in the Unified Health System SUS, the retraction of economic activity, the withdrawal of incentives in the country, a flagrant crisis in the institutions and a government that does not recognize the seriousness of the pandemic. Currently, the Federal Government demonstrates a clear lack of planning, organization and willingness to cease, albeit minimally, the damage caused by the pandemic. At this moment, the world turns its gaze to Brazil to the detriment of the lack of responsibility in dealing with the situation, it is speculated beyond the closing of borders to Brazilians, economic, political and commercial boycotts. On the subject, the World Health Organization and the Inter-American Court of Human Rights have recommended specific recommendations for dealing with the virus. However, the Federal Government seems to ignore them. Thus, the scenario that is envisaged is the increasing increase in mortality due to the virus, the collapse of the health system and the perishing of the most vulnerable groups. The growth of unemployment and the subjection of workers to subordinate workers and low pay are also evident, in addition to the evident precariousness in the work environment. We occupy the ninth place in the ranking of the most unequal countries in the world. Therefore, there is no way to avoid noticing the exponential growth in the pace of social inequality in Brazil. In fact, it intensified in the midst of the pandemic. Even with the granting of what became known as emergency aid, the kind of benefit of a installmentary nature paid to certain vulnerable categories of society for a fixed period, a measure proved to be insufficient. Currently the country continues to face constant institutional crises, it does not have a serious public policy to fight the pandemic and its reflexes, it experiences the collapse of public health in many states of the Federation, it continues without a vaccination plan and the remaining population under the sieve of the famous Brazilian way.

While the man who occupies the top of the Brazilian social castes hides from the pandemic in luxury resorts and bunkers the vulnerable survive in the chaos.

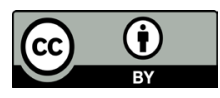

